\title{
O PDE: NOVO MODO \\ DE REGULAÇÃO ESTATAL?
}

NORA RUT KRAWCZYK

Faculdade de Educação da Universidade Estadual de Campinas

norak@unicamp.br

\section{RESUMO}

O artigo discute o papel do Estado, as relações que se estabelecem entre as diferentes esferas de governos federal e a instituição escolar, bem como as diferentes formas de regulação contidas no Plano de Desenvolvimento da Educação. Para isso analisa a gestão educacional proposta no plano e o potencial e as limitações da escolha do município como "território" privilegiado no modo de regulação educacional.

PLANO DE DESENVOLVIMENTO DA EDUCAÇÃO - ADMINISTRAÇÃO DA EDUCAÇÃO POLITICAS PÚBLICAS - POLITICAS EDUCACIONAIS

\section{ABSTRACT}

THE EDUCATION DEVELOPMENT PLAN: A NEW MODEL OF STATE REGULATION? This article discusses the role of the State, the relationships established between the different spheres of the federal government and learning institutions, as well as the different forms of regulation contained in the Education Development Plan. In order to do so, it analyses the plan's proposal of educational management and the potential and limits of the choice of the municipality as the privileged "territory" in this educational regulation model.

EDUCATIONAL ADMINISTRATION - PUBLIC POLICIES - EDUCATIONAL POLICIES 
Há conceitos que se destacam na política e no debate educacional em cada momento histórico. Na década de 1990, regulação, descentralização, desconcentração, federalismo e governança foram conceitos muito habituais na análise das políticas educacionais adotadas no Brasil, na América Latina e até mesmo em âmbito internacional.

Todos esses conceitos expressam diferentes formas de relações entre o Estado e a sociedade. Especificamente, a regulação, cujo propósito é manter a governabilidade necessária para o desenvolvimento do sistema, refere-se a um ordenamento normativo, historicamente legitimado, que medeia as relações entre Estado e sociedade, que busca a solução de conflitos e a compensação dos mecanismos de desigualdade e de exclusão próprios do modo de produção capitalista. Esses ordenamentos supõem uma concepção de organização social, política e econômica, a partir da qual se definem responsabilidades e competências do Estado, do mercado e da sociedade, e tendem, também, a desencadear processos de ressocialização (Krawczyk, 2005).

A importância que tomaram no debate educacional as diferentes formas de relações entre o Estado e a sociedade provém das reformas educacionais iniciadas na década de 1990 na América Latina, no bojo de profundas transformações econômicas, políticas e sociais nacionais e internacionais que pretendiam reformular radicalmente essas relações.

Essas reformas foram elaboradas sob a égide de uma forte crítica às funções dos Estados nacionais e à lógica de gestão pública no modelo de desenvolvimento keynesiano', crítica essa decorrente da crise que nesse momento vivia o processo de acumulação capitalista. $O$ Estado deixou de ser visto como parceiro estratégico do mercado ao definir políticas econômicas e sociais tais como as promovidas pelo Estado de bem-estar social.

Através de um processo de indução externa que possibilitou o estabelecimento de uma regulação supranacional ${ }^{2}$, foram impostas mudanças não apenas

I. No interior da crise do Estado de bem-estar social nos países desenvolvidos e da crise do nacional-desenvolvimentismo nos países do Terceiro Mundo.

2. Regulação transnacional é um conceito cunhado por Barroso que significa "o conjunto de normas, discursos e instrumentos (procedimentos, técnicas, materiais diversos, etc.) que são produzidos e circulam nos fóruns de decisão e consulta internacionais, no domínio da educação, e que são tomados, pelos políticos, funcionários ou especialistas nacionais, como "obrigação" ou "legitimação" para adaptarem ou proporem decisões ao nível do funcionamento do sistema educativo" (Barroso, 2006, p.44). 
para a reformulação do papel do Estado na provisão de bens e serviços sociais, reservando-Ihe as funções de coordenação e regulamentação, mas também para a substituição do controle centralizado pela incorporação da iniciativa privada e individual na gestão pública.

Uma pesquisa sobre as reformas educacionais efetivadas na década de 1990 na Argentina, no Brasil, Chile e México mostrou que a descentralização do sistema educacional para as diferentes instâncias governamentais, com a minimização da responsabilidade do Estado pela educação, é comum a todos os países. No entanto, observam-se diferenças significativas na regulação desse processo que vão desde a mera transferência dos serviços educacionais até a forte regulamentação do financiamento da educação (Krawczyk, Vieira, no prelo).

A reforma educacional no Brasil iniciou-se na segunda metade da década de 1990 com o intuito de consolidar uma nova forma de gestão da educação e da escola e, ao mesmo tempo, de reverter o exíguo atendimento dos ensinos fundamental e médio, bem como os altos índices de fracasso e evasão escolar.

A reconfiguração do papel do Estado com a institucionalização do Estado mínimo resultou, no caso da educação, em um processo de centralização/ descentralização em que o governo federal ficou responsável pela definição de parâmetros curriculares nacionais e pela implantação de um sistema de avaliação institucional comum para o país - concentrando a direção e o controle de todo o sistema educacional -, enquanto se ampliava a responsabilidade dos estados e dos municípios quanto à gestão e ao provimento da educação à população em todos os níveis, embora os recursos fossem canalizados prioritariamente para o ensino fundamental.

A descentralização já era uma característica constituinte da educação formal no Brasil. A educação primária e a secundária foram organizadas sob a responsabilidade dos estados e/ou municípios, conformando várias redes de ensino em todo o país. Esse caráter descentralizado da educação formal originou-se, principalmente, da omissão do poder público, do embate de diferentes projetos societários das elites locais e, em menor medida, da organização federativa do país. Esses conflitos acompanharam também a lógica de distribuição das competências entre as diferentes esferas de governo - União, estados e municípios - ao longo do século XX.

Com a implantação, em 1996, do Fundo de Manutenção e Desenvolvimento do Ensino Fundamental e de Valorização do Magistério - Fundef -, a 
educação pública no Brasil sofreu forte regulamentação, pelo menos no âmbito financeiro, que afetou a distribuição de responsabilidades e de atribuições entre as diferentes esferas de governo e a redistribuição de recursos em cada estado da federação.

A nova forma de gestão da educação implicou também mudanças institucionais e a reconfiguração das relações entre o Estado a escola e a comunidade. Abriu-se espaço para a participação da iniciativa privada nos projetos e nas práticas institucionais das escolas públicas e, ao mesmo tempo, estabeleceu-se um canal de comunicação entre o governo central e as unidades escolares. Este último, principalmente por meio de programas que vinculavam o recebimento de recursos federais extras e de premiações à elaboração de projetos que seriam avaliados pelo Ministério da Educação - MEC.

Assim como o Brasil, outros países latino-americanos implementaram políticas educacionais orientadas por uma nova forma de gestão da educação e da escola. O redimensionamento das funções do Estado mostrou-se variado e complexo nos diferentes países da região, mas não se vislumbram com clareza, ao longo dos primeiros dez anos de implementação da reforma, uma dinâmica estatal e uma nova forma de regulação educacional que tenham se tornado hegemônicas na região (Krawczyk, Vieira, no prelo).

Passados cinco anos de gestão do Partido dos Trabalhadores - governo Lula -, o MEC lança um Plano de Desenvolvimento da Educação - PDE - e o apresenta à sociedade como a expressão de uma mudança essencial no papel do Estado. Como disse recentemente o ministro de Educação, Fernando Haddad, em sabatina realizada pelo jornal Folha de S. Paulo ${ }^{3}$, o Estado deve ser não somente avaliador, mas também regulador.

Com a implantação do PDE, o poder executivo busca reverter várias situações que tornaram difícil a governança da área: o crescimento desmedido do número de municípios; a segmentação territorial constitutiva da educação pública; a diminuição da responsabilidade da União com a educação; a proliferação de programas desarticulados entre si, vinculados à mudança da gestão escolar e à melhora da aprendizagem no ensino fundamental; a privatização acelerada da educação superior na década de 1990; a ausência de um regime de colaboração no processo de municipalização deslanchado dez anos atrás;

3. Sabatina realizada no dia 25 de março de 2008. 
o velho debate em torno da constituição de um sistema nacional de educação; e os baixos índices de rendimento escolar na rede de educação pública em todo o país.

No PDE, que é um plano de ação plurianual 2008/20 I I ${ }^{4}$, reúnem-se 52 ações que cobrem todas as áreas de atuação do MEC e incidem sobre uma série de aspectos nos diferentes níveis de ensino, visando o objetivo comum de melhorar a qualidade da educação. Quase todas essas ações já vinham sendo desenvolvidas, embora haja algumas novas, inspiradas em ações implementadas por organizações não governamentais - ONGs - em escolas públicas.

A variedade das ações contempladas no PDE resulta, segundo o MEC, de uma "visão sistêmica" da política educacional, que se oporia a uma "visão fragmentaria" do governo de Fernando Henrique Cardoso (I 995-2002). Com essa perspectiva, o plano elaborado prevê ações para todos os níveis de ensino e para as diferentes necessidades institucionais, visando romper o que qualifica como falsas oposições entre educação fundamental e educação superior, entre educação fundamental e os outros níveis de ensino na educação básica, entre o ensino médio e a educação profissional, além de outras. Mantém-se, contudo, o espírito de focalização da política educacional, não como princípio, mas como estratégia de equalização, tal como se verá adiante.

A diversidade de aspectos previstos pelas ações do PDE expressa também, sem dúvida, as desigualdades entre as escolas do país quanto às condições de aprendizagem e aos recursos materiais e humanos. $\bigcirc$ plano reflete o paradoxo dessa situação, ao contemplar desde a instalação de luz elétrica em todas as escolas até a implantação da alfabetização digital.

\section{UMA NOVA ENGENHARIA DE GESTÃO EDUCACIONAL}

Concomitantemente ao lançamento do PDE, foi promulgado o Decreto n. 6.094, contendo um Plano de Metas intitulado "Compromisso Todos pela Educação", ao qual os municípios e os estados devem aderir por uma espécie de contrato territorial entre as diferentes esferas de governo para poder receber transferências voluntárias de recursos financeiros e assistência técnica

4. A obrigatoriedade de elaboração de um plano plurianual de quatro anos (inclui o primeiro ano de mandato do sucessor para evitar descontinuidades) está estipulada na Constituição de 1988 para todas as pastas do governo federal. 
do governo federal. $O$ termo de adesão, ou contrato territorial, requer a elaboração de um plano de atividades articuladas (PAR) municipal e/ou estadual.

O MEC teve como parceiro privilegiado para a elaboração das metas que se pretende atingir até 20 I I um grupo empresarial que, em uma atitude bastante propositiva, havia lançado, em outubro de 2006, o Movimento Compromisso Todos pela Educação, nome com o qual foi batizado também o plano de metas promulgado pelo governo federal.

Como afirma Saviani, ainda que possa ser positiva a iniciativa do MEC de capitalizar a receptividade da opinião pública para a questão da qualidade de ensino, expressada por setores influentes na mídia

... é preciso cautela para não cairmos na ingenuidade de acreditar, sem reservas, nas boas intenções que agora, finalmente, teriam se apoderado de nossas elites econômicas e políticas. Com efeito, se o MEC seguir na trilha proposta pelo movimento empresarial Compromisso Todos pela Educação, os limites do PDE resultarão incontornáveis. (2007, p. I.25I)

O PDE apresenta-se como uma política nacional e um arranjo institucional resultante de uma revisão das responsabilidades da União, que passa a assumir o compromisso do combate às desigualdades regionais e da construção de um mínimo de qualidade educacional para o país. Adjudica ao governo federal o papel regulador das desigualdades existentes entre as regiões do Brasil por meio de assistência técnica e financeira, de instrumentos de avaliação e de implementação de políticas que ofereçam condições e possibilidades de equalização das oportunidades de acesso à educação de qualidade. Por sua parte, os estados e, principalmente, os municípios assumirão o compromisso pelo desenvolvimento educacional em seus "territórios".

Desse modo, sem negar a tensão própria da forma de governo federalista em favor da coexistência de autonomia das diferentes esferas de governo e a preservação simultânea da unidade e da diversidade da nação, seria possível a construção da unidade dos sistemas educacionais como sistema nacional - o que pressupõe multiplicidade, não uniformidade. Essa multiplicidade seria garantida pelos necessários enlaces da educação com a ordenação do território e com o desenvolvimento econômico e social, única forma de assegurar a todos e a cada um o direito de aprender. 
A complexidade de país federativo impõe, a qualquer engenharia política que pretenda operacionalizar o princípio de regime de colaboração estipulado constitucionalmente, o desafio de lidar com uma série de contradições presentes nessa forma de governo, como unidade versus diversidade, poder local versus poder geral e união versus autonomia.

No PDE estabelece-se nova forma de relação intergovernamental que interpreta o regime de colaboração, enunciado na Carta de 1988, como o compartilhamento de

... competências políticas, técnicas e financeiras para a execução de programas de manutenção e desenvolvimento da educação, de forma a concertar a atuação dos entes federados sem ferir-thes a autonomia. Essa simples divisão de tarefas, se articulada em grandes eixos (educação básica, superior, profissional e continuada), com regras transparentes e metas precisas, passíveis de acompanhamento público e controle social, pode pôr em marcha um avanço perceptível e sólido... (Brasil, 2007, p. 10)

Segundo o atual ministro da Educação, uma das inovações importantes do PDE é o acréscimo de metas qualitativas e intermediárias às metas quantitativas já estipuladas no Plano Nacional de Educação - PNE. As metas intermediárias serão definidas a cada dois anos, tanto para as redes de ensino como para as instituições escolares. Essa diversidade de metas - quantitativas e qualitativas, intermediárias e finais - concatena-se com dois eixos fundamentais do PDE: a responsabilização da classe política, juntamente com o comprometimento dos gestores e dos docentes das escolas, e a mobilização social.

Além do regime de relação intergovernamental que acabamos de explicar, o governo federal pretende articular as ações dos diferentes ministérios, de modo tal que as políticas públicas possam interagir entre elas, principalmente com a pasta da Educação. Assim, o Plano de Desenvolvimento da Educação e o Plano de Aceleração do Crescimento - PAC - passariam, juntos, a ser a alavanca do desenvolvimento nacional. Este alinhamento justifica-se pela necessidade de que os investimentos em infra-estrutura sejam acompanhados de investimentos em educação, com vistas a aumentar o crescimento do país. 
Um aspecto a destacar na promoção da interação entre todas as políticas públicas é o fato de que a unidade escolar passa a ser o eixo norteador. Por exemplo, quadras esportivas devem ser construídas perto das escolas e as equipes do Programa de Saúde das Famílias devem passar a visitar também as escolas 5 . É interessante explorar a idéia da unidade escolar como eixo norteador das políticas públicas nos municípios para revalorizar a escola no seu pequeno território (bairro) e para que ela volte a ser reconhecida como um espaço cultural e de congregação da comunidade.

\section{AS CONEXÕES ENTRE AVALIAÇÃO, GESTÃO E FINANCIAMENTO SERIAM INÉDITAS?}

O MEC chama a si a responsabilidade de atuar de forma mais incisiva na indução de uma educação básica de qualidade. Para isso, define vários mecanismos de controle da ação municipal. Além do termo de compromisso que formaliza a adesão dos municípios em troca de assistência técnica e apoio financeiro, foi implantado um Sistema de Monitoramento - Simec - para acompanhar as ações do PDE e dos planos de ações articuladas - PAR - empreendidos por estados e municípios para a melhora das condições da educação básica. Além disso, o PDE criou um novo indicador de avaliação de rendimento, o Índice de Desenvolvimento de Educação Básica - Ideb.

Principal proposição do PDE, o Ideb possibilita combinar os resultados de desempenho escolar obtidos na Prova Brasil com os resultados de rendimento escolar e o fluxo de alunos apurados pelo censo escolar. A maioria das ações do governo está atrelada a esse indicador em cada estado e/ou município. O MEC afirma que

... O PDE promove profunda alteração na avaliação da educação básica. Estabelece, inclusive, inéditas conexões entre avaliação, financiamento e gestão, que invocam conceito até agora ausente do nosso sistema educacional: a responsabilização e, como decorrência, a mobilização social. (Brasil, 2007, p. 19)

5. Exemplos dados pelo ministro de Educação na sua palestra de abertura no Seminário Itinerante: O Plano de Desenvolvimento da Educação em Debate nas Universidades Públicas Paulistas, São Paulo, Campinas e Rio Claro, de 15 a 18 de outubro de 2007. 
Assim, da revisão do papel do governo federal resulta um controle maior e sistemático das políticas nos entes federados; o atrelamento dos recursos próprios do MEC aos resultados do Ideb; a interlocução direta com as unidades escolares, por meio, principalmente, da definição de metas para cada uma delas e da manutenção do Programa Dinheiro Direto na Escola, iniciado no governo de Fernando Henrique Cardoso, que associa recursos adicionais à aprovação do projeto pedagógico da instituição.

Sem entrar no mérito da concepção do Ideb, fica clara a valorização exacerbada da interferência de instrumentos de avaliação para a mudança da realidade educacional brasileira.

As conexões entre avaliação, gestão e financiamento na verdade não são inéditas. Pelo contrário, foi na década de 1990, no bojo de mudanças radicais do papel do Estado na educação, que a avaliação passou a ser o instrumento principal de regulação prevendo que os recursos acompanhassem os bons resultados. A originalidade limita-se ao fato de não somente prescrever recursos financeiros vinculados a um bom rendimento institucional - seja quanto ao Ideb, seja quanto à capacidade de elaboração de planos de ação -, como também oferecer atendimento prioritário aos municípios com os mais baixos índices, que precisarão de mais apoio para melhorar sua situação educacional. Trata-se, segundo o MEC, de municípios carentes de recursos financeiros e humanos que nunca conseguiram nenhum tipo de benefícios, e por isso a educação que oferecem é tão precária. $\bigcirc$ Ideb visa

... identificar as redes e as escolas públicas mais frágeis a partir de critérios objetivos e obriga a União a dar respostas imediatas para os casos mais dramáticos ao organizar o repasse de transferências voluntárias com base em critérios substantivos, em substituição ao repasse com base em critérios subjetivos. (Brasil, 2007, p.23)

A proposta de que o Ideb "costure" a política educacional dos próximos quatro anos responde não somente a uma tendência internacional de sobrevalorização da avaliação como estratégia de mudança para aumentar a competitividade das instituições, mas também à necessidade de melhora rápida do país em relação aos indicadores educacionais no plano internacional. De fato, nos últimos anos, o Brasil vem melhorando sua posição em vários rankings 
internacionais, como o Índice de Desenvolvimento Humano - IDH -, reduziu o risco país e recentemente atingiu o grau de investimento, mas não apresenta melhoras nos indicadores educacionais que se mantêm constrangedores no plano internacional.

\section{O QUE AINDA FICA FORA DO CONTROLE DO PODER PÚBLICO FEDERAL}

O PDE refina o indicador de qualidade, incluindo o fluxo dos alunos com o propósito de evitar a mera aprovação automática destes sem que o seu rendimento esteja assegurado, mas mantém o suposto que se ancora na importância do Estado avaliador. Nesse caso, a importância da avaliação não se restringe à possibilidade de acompanhamento do desempenho dos alunos para a correção de rumos na política educacional e/ou à necessidade de informação sobre a situação educacional do país; acrescenta a necessidade de divulgação de seus resultados como instrumento de promoção do controle e da responsabilidade social com o aprendizado (comunidade de pais, professores e dirigentes políticos).

O MEC pressupõe, a partir da implementação do Ideb, que equaciona rendimento dos alunos com fluxo escolar, que conseguirá inibir os mecanismos de manipulação dos dados das escolas e/ou do poder político, assim como o favoritismo na distribuição de financiamento voluntário da União. No entanto, não ficam claros os mecanismos de controle para que essa manipulação não aconteça, nem para coibir os comportamentos perversos e antidemocráticos suscitados pela divulgação de resultados de avaliações institucionais no conjunto do sistema.

Recentemente foi publicado nos jornais um ranking de escolas de ensino médio com base nos resultados do Exame Nacional de Cursos - Enem -, e seguiram-se vários artigos tentando descobrir "o que faz a diferença". Para visualizar o potencial e os riscos desse tipo de ranking para o aumento da responsabilização e da mobilização social, tal como sugere o MEC com o Ideb, é necessário levar em conta a conduta da mídia, dos órgãos governamentais e das próprias instituições escolares.

A imprensa revelou, por exemplo, que a escola posicionada em segundo lugar no ranking é uma instituição privada em que os alunos são agrupados em 
turmas homogêneas com base no rendimento e os reprovados são expulsos. Em outras escolas, soube-se que, para obter melhores resultados nos rankings de rendimento institucional, decidiu-se utilizar as provas de anos anteriores do Enem nas tarefas e nos exames. Também foram mencionadas instituições que cobram mensalidade entre $R \$ 1.000$ e $R \$ 2.500$ e têm alta demanda, porque oferecem um leque variado de disciplinas e jornada escolar densa.

Nada disso é novo, mas mostra mais uma vez as estratégias perversas que as instituições adotam para responder às demandas por qualidade, principalmente quando o aumento de recursos e/ou de prestígio depende de seu rendimento em provas nacionais.

O MEC remete-se implicitamente à política educacional do governo que o antecedeu, quando declara, no documento do PDE, ser contrário a um sistema de incentivos composto por prêmios e punições às escolas ou às redes educacionais conforme cumpram ou não as metas de qualidade, em geral preestabelecidas. Em contrapartida, propõe-se ir ao encontro dos mais necessitados por meio do aumento das transferências automáticas ${ }^{6}$ da União às escolas e às redes educacionais que "demonstrem capacidade de avançar com suas próprias forças e o aumento das transferências de recursos condicionados à elaboração e ao cumprimento de um plano de trabalho para as escolas e as redes educacionais que necessitem apoio técnico e financeiro" (Brasil, 2007, p.4I).

Essa declaração refere-se à decisão do governo federal de realizar um atendimento prioritário aos municípios com Ideb mais baixo, como também às escolas municipais e estaduais com baixo rendimento por meio do PDEEscola, que destina parte dos recursos da União diretamente às instituições escolares.

A liberação desses recursos é condicionada à elaboração, pela comunidade escolar, de um diagnóstico das dificuldades e de um plano de gestão com ações e metas capazes de mudar os baixos indicadores educacionais, com prazos para alcançá-las e com a previsão dos recursos necessários. O MEC disponibiliza apoio técnico para as equipes escolares que tenham dificuldade de elaborar seu plano. Os recursos são transferidos por meio do Programa

6. Transferências automáticas são aquelas que complementam os recursos dos estados e municípios. 
Dinheiro Direto na Escola - PDDE -, que prevê assistência financeira às escolas públicas, em caráter suplementar, para a cobertura de despesas de custeio, de manutenção e para pequenos investimentos.

Ao longo do documento explicativo do PDE encontram-se várias referências ao aumento do financiamento por parte da União, visando equalizar as oportunidades educacionais. No entanto, além de os recursos adicionais ainda serem condicionados à aprovação de plano de trabalho institucional, o PDDE prevê mais recursos para as escolas que melhorarem seu Ideb. Ou seja, essas escolas serão premiadas.

Continua-se, portanto, insistindo no pressuposto de que os municípios e as escolas necessitam fazer diagnósticos para encontrar soluções, como se docentes e gestores educacionais não soubessem quando a educação em seu município vai mal, e como se as soluções fossem simples e resultassem de atos de boa vontade, como afirma a professora Arelaro no Seminário Itinerante.

De fato, essa forma de conceber a construção de estratégias políticoeducacionais, que começa com a elaboração de um diagnóstico para identificar os principais problemas e conclui com a definição de ações institucionais, já vem sendo ensaiada há pelo menos uma década. Acumulam-se "diagnósticos" que servem mais para cumprir burocraticamente a condição estipulada para o recebimento de recursos financeiros do poder público do que para orientar as ações e encontrar saídas.

Enquanto isso, muitas Secretarias de Educação municipais, principalmente as que não possuem bagagem própria de gestão da educação, pressionadas a promover mudanças rápidas e efetivas, tendem a procurar o mercado educacional para preencher suas lacunas, tornando-se as prefeituras novos nichos que se abrem para as iniciativas comerciais. É o caso recente de adoção, em alguns municípios, de apostilas e outros materiais didáticos elaborados por grupos privados.

Pesquisas acadêmicas realizadas na última década em diferentes países mostram que projetos que deveriam definir uma proposta político-educacional coletiva para a escola e ser inovadores quanto às práticas pedagógicas se transformaram em atividades burocráticas que muitas escolas têm dificuldade de assumir, o que as leva a recorrer à ajuda de técnicos externos à instituição. 


\section{A ESCOLHA DO MUNICÍPIO COMO TERRITÓRIO PRIVILEGIADO}

O PDE tem como um dos eixos principais a territorialidade, porque é no território "que as clivagens culturais e sociais, dadas pela geografia e pela história, se estabelecem e se reproduzem" (Brasil, 2007, p.6). No marco de enlace entre educação e ordenação territorial, o PDE dirige-se principalmente ao município, com suas duas redes públicas de ensino. Ou seja, privilegia o espaço territorial em que a educação acontece, sem privilegiar uma ou outra rede de ensino público. Por isso, o compromisso de adesão ao Plano não se restringe às autoridades municipais, mas inclui também as estaduais.

A proposta de demarcar territorialmente as ações do PDE permite, segundo o MEC, identificar as regiões que foram relegadas ao descaso nos últimos anos e que necessitam ser resgatadas para lograr a equidade educacional no país.

O município é uma categoria que passou a ter importância e ao mesmo tempo adquiriu alto risco na definição de políticas educacionais, e por isso vem ganhando espaço nos estudos sobre os problemas sociais brasileiros (rural/ urbano, concentração populacional, política local, disparidades intramunicipais). Essa crescente importância deve-se à focalização das políticas na esfera local, mas também ao grande aumento do número dos municípios a partir da década de 1990.

Entre 1988 e 200 I foram criados 1.377 municípios, o que corresponde a 25\% de todos os existentes no país. Um período anterior em que também houve grande fragmentação pela criação de municípios no Brasil foi o compreendido entre 1940 e 1970, quando surgiram 2.377 novos desses entes federados. Esse processo apoiou-se no caráter descentralizador da Constituição de 1946, que conferiu maiores prerrogativas aos municípios brasileiros (Simões, 2004).

A luta dos entes federados por maior descentralização fiscal e política após vinte anos de intensa centralização sob o regime ditatorial resultou na ampliação da autonomia dos estados e municípios, adquirida na Constituição de 1988. Esta caracterizou-se, segundo Affonso (2000), como um processo de "descentralização pela demanda", e resultou do longo período transcorrido entre a redemocratização nos governos subnacionais e no governo federal ${ }^{7}$, o

7. A redemocratização nos estados e municípios ocorreu a partir de 1980 e somente quase dez anos depois chegou ao nível central. 
que fortaleceu a luta dos estados e municípios pela descentralização, deixando a União sem quem a defendesse na Constituição de 1988. Para o autor, "a descentralização se deu sem um projeto de articulação e sem uma coordenação estratégica" (Affonso, apud Simões, 2004, p. 134).

regime de colaboração entre as diferentes esferas de governo no provimento da educação formal traduziu-se, na Lei de Diretrizes e Bases da Educação Nacional - LDB - de 1996, em uma distribuição de responsabilidades, pela qual se produziu de fato a municipalização do ensino fundamental.

A proliferação de municípios provocou, entre outras coisas, o enfraquecimento do poder regulatório do governo federal. Para reverter essa situação e diminuir as disparidades dos recursos financeiros para a educação no interior de cada um dos estados federados, criou-se o Fundo de Manutenção e Desenvolvimento do Ensino Fundamental e Valorização do Magistério - Fundef -, um fundo fiscal que juntou os recursos das dotações orçamentárias dos estados e municípios e passou a distribuí-los de acordo com o número de alunos matriculados nas respectivas redes estaduais ou municipais de cada estado, ficando a União responsável pela complementação necessária, no caso de as escolas não receberem o mínimo designado por aluno. Em 2006, o Congresso Nacional aprovou uma lei pela qual esse fundo passou a contemplar também a educação infantil, o ensino médio e a educação de jovens e adultos, sendo denominado agora Fundo de Manutenção e Desenvolvimento do Ensino Básico e Valorização do Magistério - Fundeb.

A primeira e mais distintiva característica da federação brasileira é a acentuada desigualdade socioeconômica da qual decorrem os diferentes níveis de desenvolvimento da educação escolar nas unidades subnacionais, seja nos estados, seja nos municípios.

Um dos motivos que explicaria a impossibilidade de construção de um projeto de educação para o país terá sido o fato de que a autonomia regional preconizada desde a institucionalização do regime federativo não incorporou o preceito liberal de inclusão social (Capelato e Neves, 2004), tendo a educação se desenvolvido segundo os interesses e as características peculiares dos desenvolvimentos regionais. Constituíram-se, então, diferentes redes de ensino descentralizadas e autônomas em cada um dos estados e municípios, em momentos distintos e com características específicas. $\bigcirc$ Brasil chegou, assim, ao final do século XX, com índices muito elevados de analfabetismo e de 
evasão escolar, que estampavam o grau de desigualdade e de exclusão social que caracteriza o capitalismo no país (Carbonari, 2004).

Segundo o governo federal, com o PDE, o investimento em educação terá um aumento da ordem de $1 \%$ do Produto Interno Bruto - PIB -, incluindo a complementação de recursos que correspondem à União no Fundeb. $O$ próprio MEC reconhece que esse aumento não é suficiente, mas quer contar com o apoio dos estados e dos municípios. No debate sobre o tema também tem-se observado que os recursos remanescentes da complementação federal para o Fundeb são exíguos. Não obstante, a União tem a ambiciosa expectativa de equalizar as oportunidades educacionais, mediante esse pequeno aumento de recursos, contando com o fato de que a sua alocação segue prioritariamente o preceito de ação afirmativa.

Outra característica da federação brasileira enfatizada no PDE é a fragilidade técnica, principalmente da maioria das prefeituras, para dar conta do processo de municipalização do ensino fundamental.

A assistência técnica que o MEC disponibiliza para os estados e/ou municípios, sem entrar no seu mérito, permitirá - talvez ainda mais do que a avaliação - que ele intervenha na coordenação das redes de ensino, na microrregulação local $^{8}$, podendo, portanto, fortalecer o poder regulatório do governo central.

Mas é interessante observar na literatura a complexidade do cenário municipal no país em face da diversidade de comportamentos sociais, econômicos e demográficos e, em razão disso, as dificuldades para a definição de parâmetros de implementação de políticas públicas.

Uma delas é a relação entre a distribuição populacional e dos municípios no espaço nacional. Uma das características mais importantes dessa relação é o grande número de pequenos municípios com população rarefeita: aqueles com até 20 mil habitantes correspondem a 73\% do total, porém, abrigam um contingente de apenas 19,5\% da população. Em contrapartida, os municípios com mais de 500 mil habitantes, considerados municípios grandes, correspondem a apenas $0,6 \%$ do total, mas concentram $27,8 \%$ da população. Esses

8. A microrregulação local remete "ao complexo jogo de estratégias, negociações e ações, de vários atores, pelo quais as normas, injunções e constrangimentos da regulação nacional são (re)ajustadas localmente, muitas vezes de modo não intencional" (Barroso, 2006, p.56). 
dados indicam, por sua vez, que o ritmo de crescimento dos municípios não acompanhou o fluxo de crescimento da população e, por outro, que o processo de urbanização brasileira foi seguido de uma alta concentração populacional nos grandes centros urbanos?.

Diante desses dados, é preciso alertar, como faz a professora Sá Barretto $^{10}$, para o fato de que o PDE pode chegar a ter um forte impacto local, mas corre o risco de repercutir muito pouco quando se considera o conjunto do país, com suas dimensões continentais e com uma população que é expulsa dos municípios mais pobres pela falta de oportunidades de trabalho e de sobrevivência e acaba se concentrando principalmente nas regiões urbanas e nas grandes cidades, para onde convergem tanto a riqueza quanto a pobreza extremas.

Isso remete a outra questão importante sobre a qual existem controvérsias. Refiro-me à classificação urbano/rural dos municípios. Segundo Veiga (2003), existe uma visão distorcida do grau de urbanização do Brasil, porque, enquanto as estatísticas oficiais remetem a $81 \%$ de urbanização, sendo o rural identificado como mero resíduo e destinado ao rápido desaparecimento, outros cálculos envolvendo indicadores mais adequados, segundo o autor, revelam que no ano 2000 o espaço rural abrangia a maioria do território nacional, 4.500 municípios aproximadamente, e cerca de $30 \%$ da sua população"'.

Além das características específicas das realidades urbanas e rurais, não podemos deixar de lembrar a extrema desigualdade entre o Brasil urbano e o Brasil rural, que se manifesta principalmente, como diz Veiga (2003, p.44), "nas escolhas, nas opções e, sobretudo, nos direitos que podem ser efetivamente exercidos por essas duas partes da população".

9. Dados extraídos do Instituto Brasileiro de Geografia e Estatística - IBGE -, Indicadores Sociais Municipais 2000 (apud Simões, 2004).

10. Debatedora da mesa-redonda "O PDE e as relações entre as instâncias governamentais", no Seminário Itinerante.

I I. Em 1938, as sedes municipais existentes transformaram-se em cidades, independentemente do número de habitantes e de suas características estruturais e funcionais. Assim, pequenos povoados ou vilarejos passaram a ser considerados cidades e a lei que tornou isso possível continua em vigor. A Organização de Cooperação e de Desenvolvimento Econômico OCDE - considera que uma localidade, para ser urbana, deve ter pelo menos $150 \mathrm{hab} / \mathrm{km} 2$. Por esse critério, apenas 4 I I dos 5.507 municípios brasileiros existentes em 2000 poderiam ser considerados urbanos. 
Por último, outra questão importante quanto às diferenças entre os municípios é a ausência de um comportamento homogêneo nas dinâmicas de sua criação, situação que, de diferentes maneiras, afeta tanto as condições socioeconômicas dos municípios quanto as relações de poder e suas dinâmicas políticas.

É possível observar nos distintos períodos de grande crescimento do número de municípios que os critérios político-administrativos que mais influenciaram sua criação não resultaram necessariamente de reais necessidades de crescimento econômico e/ou de desenvolvimento sustentável, nem de uma estratégia de aproximação da comunidade local às estruturas de poder.

Na década de 1940, a criação de novos municípios resultou da maior autonomia, tanto política quanto financeira, atribuída a eles pela Constituição de 1946 e à expectativa de conseguir aumentar suas receitas.

No final da década de 1970, no bojo da luta pela democratização do país, intensificou-se a pressão dos estados e dos municípios por maior descentralização fiscal e política, em oposição à política de centralização do regime militar. Esse processo culminou com a Constituição de 1988, que promoveu maior descentralização, beneficiando os municípios em vários aspectos: adquiriram status de entes federados, o que thes conferiu maior autonomia; seus recursos fiscais aumentaram em virtude da criação de impostos próprios e do aumento das transferências efetuadas pelos estados e pela União; e conquistaram o direito de reger-se por lei orgânica própria.

O crescimento da esfera municipal a partir dos anos 1990, ancorado nos benefícios outorgados pela Carta de 1988, expressa interesses sociais distintos, que refletem não somente as determinações macropolíticas, mas também aspectos referentes à disputa em torno da hegemonia política local. Está associado à expectativa, por parte dos setores progressistas, de acercamento, pela comunidade local, às estruturas de poder; à possibilidade de construção de um espaço de produção de políticas públicas com participação social; e à necessidade de encontrar formas mais eficientes de resolver os problemas sociais. Mas é também o resultado de uma tendência internacional de descentralização da gestão pública; de disputas pela hegemonia política local e/ou pela possibilidade de mais recursos provenientes da arrecadação tributária descentralizada e por maior autotomia na alocação desses recursos (Cunha, 1991).

O PDE considera o território como categoria principal para o aumento do poder regulatório do governo federal e propõe uma forma bastante original de pensar o enlace entre educação e território, porque rompe com a lógica 
fragmentada da municipalização efetiva na década anterior. Leva a pensar o município não simplesmente como o ente federado responsável pelo ensino fundamental, mas como uma forma de demarcar as clivagens sociais, e a União, como o ente articulador e equalizador desses territórios, com a responsabilidade de diminuir as diferenças regionais, ao atuar preferentemente nos municípios mais pobres. Dessa maneira, o PDE anuncia a possibilidade de se conceber um sistema de educação no Brasil, e não um conglomerado de redes e de sistemas educacionais dispersos.

No cenário político-administrativo atual de fragmentação da educação pública é importante, sem dúvida, o enlace entre educação e ordenação territorial, tal como enunciado no PDE. No entanto, corremos o risco de encurralar no território a compreensão das desigualdades educacionais. A segmentação da educação pública, que expressa a complexa situação da desigualdade educacional no país, manifestase em múltiplas formas além da territorial, tais como a socioeconômica (público/ privada) e aquela interna de cada uma das redes educacionais públicas.

O PDE, por sua vez anuncia, que esse enlace permitirá enfrentar estruturalmente a desigualdade de oportunidades educacionais, adjudicando à grave disparidade regional presente no país a responsabilidade pela desigualdade educacional.

Esta visão e a afirmação de que a educação deve ser o eixo estruturante da ação do Estado para que o país possa continuar se desenvolvendo, tal como afirmado pelo MEC, é uma reviravolta dos velhos princípios da teoria do capital humano que inverte a relação entre educação e desigualdade social, colocando a responsabilidade sobre a primeira.

Por último, o risco principal do enlace entre educação e território é promover políticas que tendam a propiciar que os municípios se voltem para si, em lugar de abrir espaço para a discussão do cenário político-administrativo atual e para a promoção de articulações regionais (intermunicipais) capazes de mobilizar as suas dinâmicas internas e externas.

\section{REFERÊNCIAS BIBLIOGRÁFICAS}

AFFONSO, R. B. A. Descentralização e reforma do Estado: a Federação brasileira na encruzilhada. Economia e Sociedade, Campinas, v.9, n. I, 2000. Disponível em: http//www.eco. unicamp.br:888/seer/ojs/viewissue.php?id=17. Acesso em: maio 2008. 
BARROSO, J. O Estado e a Educação: a regulação transnacional, a regulação nacional e a regulação local. In: BARROSO, J. (org.). A Regulação das políticas públicas de educação. espaços, dinâmicas e actores. Lisboa: Educa, 2006. p.41-70.

BRASIL. Ministério da Educação e Cultura. O Plano de Desenvolvimento da Educação: razões, princípios e programas. Brasília, 2007.

CAPELATO, M. H. R.; NEVES, M. S. Retratos del Brasil: ideas, sociedad y política. In: TERÁN, O. (coord.). Ideas en el siglo: intelectuales y cultura en el siglo $X X$ latinoamericano. Buenos Aires: Fundación Osde/Siglo XXI, 2004. p.99-208.

CARBONARI, F. Municipalização do ensino: das velhas práticas as novas perspectivas. In: MARTINS, M. A.; OLIVEIRA, C.; BUENO, M. S. S. (orgs.). Descentralização do Estado e municipalização do ensino: problemas e perspectivas. Rio de Janeiro: DP\&A, 2004. p.2 I I-223.

CUNHA, L. A. Educação, Estado e democracia no Brasil. São Paulo: Cortez; Flacso/sede Brasil, 1991.

KRAWCZYK, N. Políticas de regulação e mercantilização da educação: socialização para uma nova cidadania? Educação\& Sociedade, Campinas, v.92, n.26, p.799-819, 2005.

KRAWCZYK, N.; VIEIRA, V. L. A Reforma educacional na América Latina: uma perspectiva histórico-sociológica (Argentina, Brasil, Chile e México na década de 1990), no prelo.

SAVIANI, D. O Plano de Desenvolvimento da Educação: análise do projeto do MEC. Educação \& Sociedade, Campinas, v.28, n. 100 (esp.), p. I.23। - I.255, 2007.

SEMINÁRIO ITINERANTE: O PDE em Debate. São Paulo: USP; Unicamp; Unesp, set. 2007. Disponível em: http://www.cameraweb.unicamp.br/fe/seminarioPDE. Acesso em: maio 2008.

SIMÕES, A. G. M. População, federalismo e criação de municípios no Brasil: uma análise dos casos de Minas Gerais e Rio Grande do Sul. In: ENCONTRO NACIONAL DE ESTUDOS POPULACIONAIS, I4. Anais. Caxambu, ABEP, 2004. Disponível em: http//www.abep.nepo. unicamp.br/site_eventos_abep/PDF/ABEP2004_40.pdf. Acesso em: maio 2008.

VEIGA, J. E. Cidades imaginárias: o Brasil é menos urbano do que se calcula. Campinas: Autores Associados, 2003.

Recebido em: maio 2008

Aprovado para publicação em: julho 2008 